\title{
Detection of SRS19-6MuLV in mouse dendritic cell sarcoma and its tumorigenesis
}

\author{
YANYAN LIU, XIAOCUI BIAN, BEI GU, HAILIANG FENG, \\ ZHENLI YANG, MIN ZHANG, WENJING ZHAO and YUQIN LIU \\ Department of Pathology, Institute of Basic Medical Sciences, Chinese Academy of Medical Sciences \\ and Peking Union Medical College, Tsinghua University, Beijing 100005, P.R. China \\ Received March 4, 2011; Accepted May 31, 2011
}

DOI: $10.3892 / \mathrm{mmr} .2011 .502$

\begin{abstract}
SRS19-6MuLV is a member of the MuLV family originally isolated from the Tianjin-Shanghai-Zunyi complex of murine leukemia. A notable characteristic of this virus is that it induces tumors of multiple hematopoietic lineages, including myeloid, erythroid, T-lymphoid and B-lymphoid. In a previous study, a sequence with high homology to SRS19-6MuLV in a murine dendritic cell sarcoma (DCS) was identified through cDNA expression screening with $\mathrm{mAb}$ 983D4. To investigate the relationship between SRS196MuLV and DCS, the existence of a specific SRS19-6MuLV DNA fragment in DCS cells, 15 murine tumor cells, 2 murine tumor tissues, 12 normal murine cells/tissues, 11 human tumor cell lines and SRSV/3T3 (NIH/3T3 cells infected with SRS cell supernatant) was detected by PCR. The specific fragment of SRS19-6MuLV was detected in DCS, mouse fore-gastric cancer cells, LII tumor tissue from which DCS is derived and SRSV/3T3. In addition, the integration sites of SRS19$6 \mathrm{MuLV}$ in the positive cells were examined by inverse PCR. Thus, 7 integration sites for SRS19-6MuLV were detected in DCS and 3 in SRSV/3T3. Analysis of sequences by BLAST revealed that some of the integration sites were associated with common fragile sites and some Ras-regulating miRNAs. Our results indicate that SRS19-6MuLV not only induced four types of leukemia, but also induced DCS. This virus does not infect human cells. Multiple integration of SRS19-6MuLV into chromosomes around fragile sites accounts for its carcinogenic effects.
\end{abstract}

Correspondence to: Dr Yuqin Liu, Department of Pathology, Institute of Basic Medical Sciences, Chinese Academy of Medical Sciences and Peking Union Medical College, Tsinghua University, Beijing 100005, P.R. China

E-mail: liuyuqin@public.bta.net.cn

Key words: SRS19-6MuLV, dendritic cell sarcoma, inverse PCR, integration site, miRNA

\section{Introduction}

SRS19-6MuLV, which was isolated from the Tianjin-ShanghaiZunyi (TSZ) complex of murine leukemia in the 1960s, is a murine leukemia retrovirus. Unlike other murine leukemia viruses that cause individual types of leukemia, SRS19$6 \mathrm{MuLV}$ can cause at least four kinds of leukemia, including erythroid, myeloid, T-lymphoid and B-lymphoid (1,2). In a previous study, we identified a sequence with high homology to SRS19-6MuLV in a murine dendritic cell sarcoma (DCS) through cDNA expression screening with mAb 983D4 $(3,4)$. The DCS cell line originated from a LII tumor tissue, as did the other leukemia cell lines in the TSZ complex. DCS is a sarcoma of dendritic cell (DC) origin and the direct origination of DCs from hematopoietic stem cells has been supported by expression chip analysis (5). Genomic analysis of DCS suggest the existence of a viral gene; secretion proteome studies also revealed the existence of a viral envelope-like protein (6). These results suggest a possible connection between SRS19-6MuLV and murine DCSs. Retroviruses that do not carry oncogenes usually induce tumors in susceptible host animals by proviral insertional mutagenesis, in which proto-oncogenes are activated via promoter or enhancer insertion as a consequence of integrating the viral DNA genome into the host cell chromosome (7).

The purpose of this study was to investigate the relationship between SRS19-6MuLV and DCS. Using PCR and inverse PCR (IPCR) (8-10), the existence of SRS19-6MuLV in different cells and tumors was explored and multiple integration sites were identified.

\section{Materials and methods}

Cell culture and animals. The mouse/human cell lines and mouse tumor tissues (Table I) used in this study were obtained from the Cell Resource Center, Institute of Basic Medical Sciences, Chinese Academy of Medical Sciences and Peking Union Medical College. The cells were cultured according to the recommended protocol (http://www.cellresource.cn), and grown in $5 \% \mathrm{CO}_{2}$ at $37^{\circ} \mathrm{C}$. The mice used in this study were SPF [Scxk (jing) 2009-0017] and were obtained from the Resource Center for Experimental Animal, National Institution for Food and Drug Control. The thawed cell suspensions of 
LII and FC were injected subcutaneously into 615 male mice weighing 16-18 g, aged 4-6 weeks.

SRS19-6MULV DNA determination by PCR. The genomic DNA of the cultured cells and tissues was isolated using the PureLink Genomic DNA kit (Invitrogen), following the manufacturer's instructions. A pair of primers (F, 5'-ACC TCCAGTCAAGCTACCCCAATAT-3' and R, 5'-TGGCTC ATACTCCAAAGGTT-3') that amplify a 1,401-bp fragment of SRS19-6MuLV end sequences (GenBank AF019230.1), including the SRS19-6MuLV' specific PRO-HV area (11), were designed with Primer Premier 5. For PCR reactions, a $50 \mu \mathrm{l}$ reaction mixture was prepared by adding $5 \mu \mathrm{l}$ of template genomic DNA, $25 \mu \mathrm{l}$ of $2 \mathrm{X}$ EasyTaq PCR Supermix (TRANS), $2 \mu 1$ each of primers $(10 \mu \mathrm{M})$ and $16 \mu 1 \mathrm{H}_{2} \mathrm{O}$. A total of 30 cycles of PCR were carried out, each consisting of $94^{\circ} \mathrm{C}$ for $30 \mathrm{sec}, 58^{\circ} \mathrm{C}$ for $30 \mathrm{sec}$ and $72^{\circ} \mathrm{C}$ for $80 \mathrm{sec}$. The 1,401-bp fragment of SRS19-6MuLV was amplified in genomic DNA from 15 samples of murine tumor cells, 2 samples of murine tumor tissue, 12 samples of murine normal cells/ tissues, 11 samples of human tumor cell lines and SRSV/3T3. The amplified fragments were sequenced (Sangon) and compared to SRS19-6MuLV gene sequences (GenBank AF019230.1) using DNAMAN.

Examination of SRS19-6MULV particles by transmission electron microscopy (TEM). DCS and SRSV/3T3 cells were harvested during the logarithmic phase and $1 \times 10^{6}$ cells were aliquoted into $1.5-\mathrm{ml}$ centrifuge tubes after washing twice in PBS. After washing, $1.4 \mathrm{ml}$ of $2.5 \%$ glutaraldehyde was added gently to the centrifuge tubes, which were then stored at $4^{\circ} \mathrm{C}$. Ultrathin sections were prepared and analyzed by TEM (JEOL JEM-1010, the core instrument facility, CAMS/ PUMC).

Cloning of the SRS19-6MuLV integration sites by IPCR. Genomic DNA $(1 \mu \mathrm{g})$ was digested for $1-6 \mathrm{~h}$ at $37^{\circ} \mathrm{C}$ with BamHI (Takara), cutting the $3^{\prime}$ end of SRS19-6MuLV at nucleotide position 7164 (Fig. 1). After digestion, the enzyme was heat-inactivated at $68^{\circ} \mathrm{C}$ for $10 \mathrm{~min}$. Digested DNA was ligated using T4 DNA Ligase (Fermentas) for $10 \mathrm{~min}$ at $22^{\circ} \mathrm{C}$ at a DNA concentration of $2 \mathrm{ng} / \mu 1$, and then heat-inactivated at $70^{\circ} \mathrm{C}$ for $5 \mathrm{~min}$. Two pairs of nested primers (F1, 5'-GTTGCCCCAAAGACCTGAAACGACC-3' and R1, 5'-GTAGTTCCTGTTCCTATCCCTGCGG-3'; F2, 5'-CCTG AAACGACCTTGCGCCTCATTTGAA-3' and R2, 5'-AACA ATAGGGCCAATGTTAACGACACCG-3') were designed. For the first PCR reaction, $20 \mu 1$ of reaction mixture was prepared by adding $8 \mu \mathrm{l}$ of template cyclized genomic DNA, $10 \mu 1$ 2X Premix LA Taq (Takara), and $1 \mu 1$ each of F1 and $\mathrm{R} 1$ primers $(10 \mu \mathrm{M})$. Then, 30 cycles of PCR were carried out $\left(98^{\circ} \mathrm{C}\right.$ for $10 \mathrm{sec}, 68^{\circ} \mathrm{C}$ for $\left.4 \mathrm{~min}\right)$. Using $1 \mu \mathrm{l}$ of the first-round PCR product as a template, 30 cycles of second-round PCR were carried out with primers $\mathrm{F} 2$ and $\mathrm{R} 2\left(98^{\circ} \mathrm{C}\right.$ for $10 \mathrm{sec}$, $68^{\circ} \mathrm{C}$ for $4 \mathrm{~min}$ ). Purified PCR products were cloned into the pMD19-T vector (Takara) and sequenced.

Sequence analysis. The authenticity of the integration site sequence was verified by the following criteria: i) the sequence contained portions of both the SRS19-6MuLV
Table I. Cell lines and tumor tissues.

\begin{tabular}{|c|c|c|}
\hline & Cell lines & Origination \\
\hline 1 & DCS & Mouse dendritic cell sarcoma \\
\hline 2 & MFC & Mouse fore-stomach cancer \\
\hline 3 & YAC-1 & Mouse lymphoma \\
\hline 4 & $\mathrm{P} 3 / \mathrm{NSI} / 7-\mathrm{A}$ & Mouse myeloma \\
\hline 5 & MEL & Mouse erythroid leukemia \\
\hline 6 & RAW264.7 & Mouse macrophage leukemia \\
\hline 7 & P19 & Mouse testicular teratoma \\
\hline 8 & LA795 & Mouse lung adenocarcinoma \\
\hline 9 & B16 & Mouse melanoma \\
\hline 10 & $\mathrm{~B} 16 \mathrm{~F} 1$ & Mouse melanoma \\
\hline 11 & $\mathrm{Ca} 761$ & Mouse breast carcinoma \\
\hline 12 & P815 & Mouse mastocytoma \\
\hline 13 & CT26.WT & Mouse colon cancer \\
\hline 14 & Hepa1-6 & Mouse hepatic carcinoma \\
\hline 15 & EL4 & Mouse lymphoma \\
\hline 16 & $\mathrm{NIH} / 3 \mathrm{~T} 3$ & Mouse embryo fibroblast cells \\
\hline 17 & 3T3-L1 & Mouse embryo fibroblast cells \\
\hline 18 & WEHI-3 & Mouse blood cell \\
\hline 19 & FPC-P1 & Mouse bone narrow cell \\
\hline 20 & J774.A.1 & Mouse monocyte-macrophage cells \\
\hline 21 & NSC34 & Mouse neuron-like cells \\
\hline 22 & 3T3-Swiss & Mouse embryo fibroblast cells \\
\hline 23 & BALB/C3T3 & Mouse embryo fibroblast cells \\
\hline 24 & LII & KM mouse reticulum sarcoma \\
\hline 25 & $\mathrm{FC}$ & 615 mouse fore-stomach cancer \\
\hline 26 & K562 & Human erythromyeloid leukemia \\
\hline 27 & THP-1 & Human acute monocytic leukemia \\
\hline 28 & Daudi & Human Burkkit's lymphoma \\
\hline 29 & HL-60 & Human acute promyelocytic leukemia \\
\hline 30 & Calu-3 & Human lung adenocarcinoma \\
\hline 31 & MD-MB-435S & Human breast carcinoma \\
\hline 32 & HGC-27 & Human gastric cancer \\
\hline 33 & HeLa & Human cervical cancer \\
\hline 34 & HT-29 & Human colorectal adenocarcinoma \\
\hline 35 & HepG2 & Human hepatic carcinoma \\
\hline 36 & HCT116 & Human colorectal adenocarcinoma \\
\hline 37 & SRSV/3T3 & $\begin{array}{l}\text { Mouse NIH/3T3 cells infected } \\
\text { by supernatant of SRS cells }\end{array}$ \\
\hline
\end{tabular}

3' end DNA sequence and the linked host DNA sequence; ii) the fragment between F2 and the integration site was identical to the corresponding region of the $3^{\prime}$ end of SRS19-6MuLV, as well as the fragment between the putative BamHI cutting site and R2 (Fig. 1); and iii) the host DNA region (containing $\geq 20$ nucleotides) from the integration site sequence to the putative Bam HI cutting site showed $\geq 96 \%$ identity to the mouse genomic sequence, as shown by a BLAST homology search. Database analysis of the authenticated integration site sequences was performed by BLAST homology searches. 
A SRS19-6MuLV 3 ' end Bam HI

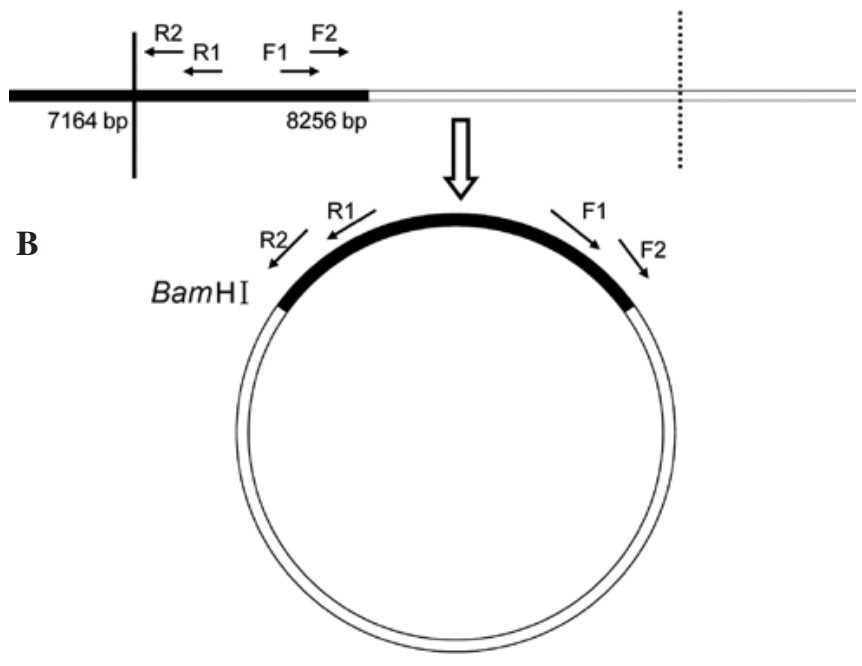

Figure 1. Schematic of inverse PCR (IPCR). (A) The shaded area denotes the region of the SRS19-6MuLV 3' end that has a BamHI cutting site. The blank area denotes flanking genomic DNA that has a putative BamHI cutting site. F1, R1 and F2, R2 denote two pairs of nested primers. (B) Circularization of this fragment puts the flanking genome DNA between the primers, and the flanking genome DNA can be amplified.

\section{Results}

Determination of SRS19-6MULV DNA in 15 mouse tumor cells. To verify the possible connection between SRS19-6MuLV and murine DCS, the 1,401-bp fragment of SRS19-6MuLV DNA was amplified in DCS cells and 14 other mouse tumor cells. Analysis of PCR products by $1 \%$ gel electrophoresis (Fig. 2A) revealed a band in the DCS and mouse fore-gastric cancer (MFC) cell lines. The PCR products of DCS and MFC were sequenced and the sequences showed $\geq 98 \%$ identity to the $1,401 \mathrm{bp}$ of the SRS19-6MuLV genome sequence.

Determination of SRS19-6MuLV DNA in 12 normal mouse cells or tissue samples. The 1,401-bp fragment of SRS19$6 \mathrm{MuLV}$ DNA was amplified in 12 normal mouse cells or tissues to verify the pathogenic specificity of SRS19-6MuLV. Analysis of PCR products by $1 \%$ gel electrophoresis (Fig. 2B) revealed that the normal cells/tissues were negative, indicating that the SRS19-6MuLV DNA fragment could only be detected in tumors.

Determination of SRS19-6MULV DNA in 2 mouse tumor tissue samples and in SRSV/3T3 cells. Since SRS19$6 \mathrm{MuLV}$ DNA was detected in DCS and MFC cells, their parent tumor tissues, LII and FC, were examined. Analysis of PCR products by $1 \%$ gel electrophoresis (Fig. 2C) revealed that LII was positive, while $\mathrm{FC}$ was negative for SRS19-6MuLV. The SRSV/3T3 cells are NIH/3T3 cells infected with SRS cell supernatant (2); our PCR results were positive for SRS19-6MuLV (Fig. 2D). The PCR products of LII and SRSV/3T3 were sequenced and the sequences exhibited $\geq 98 \%$ identity to the 1,401-bp SRS19$6 \mathrm{MuLV}$ genome sequence. These results indicate that this virus infected MFC cells during the process of subculture
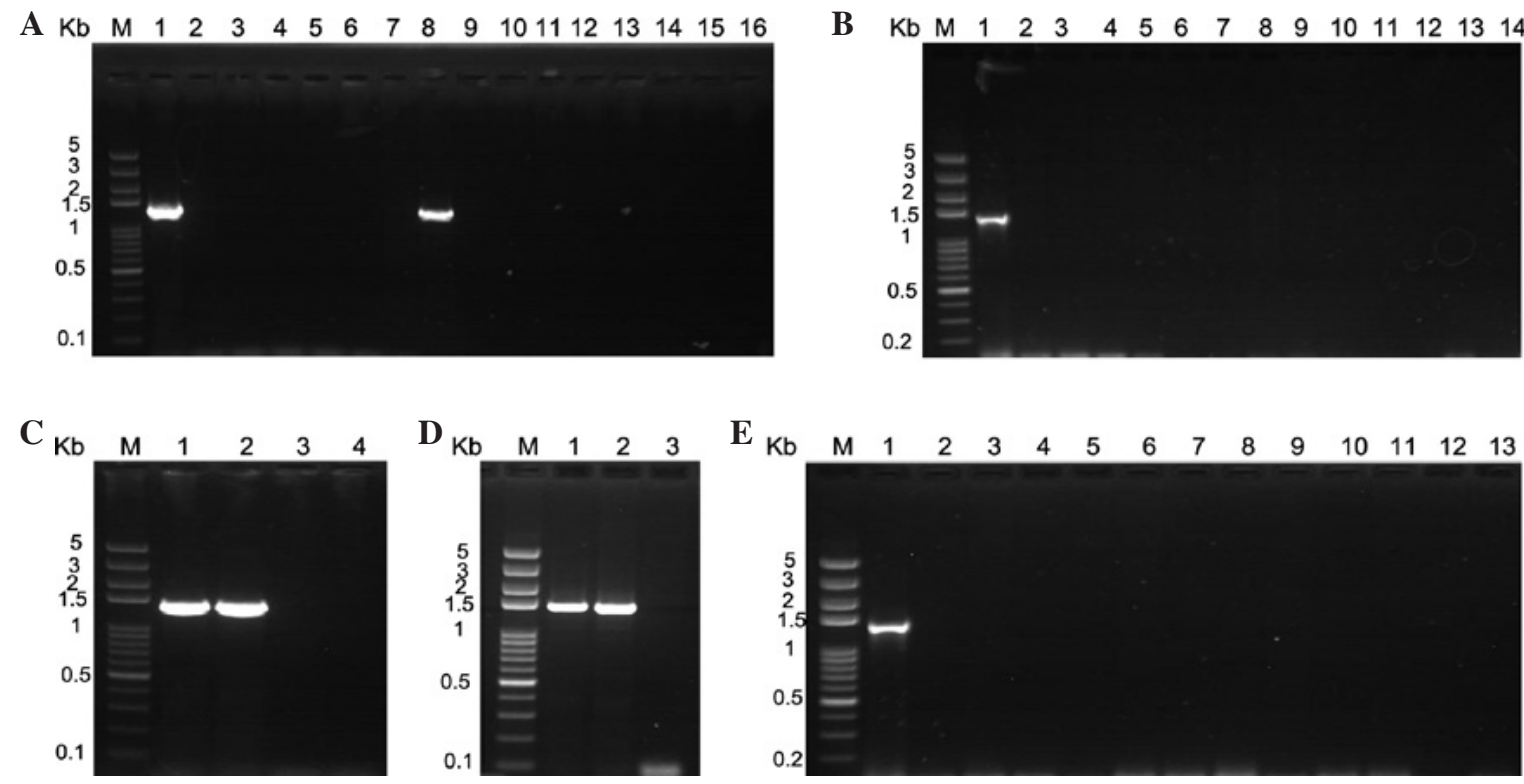

Figure 2. Amplification of SRS19-6MuLV DNA in 15 mouse tumor cells, 12 murine normal cells/tissues, 2 mouse tumor tissues, SRSV/3T3 cells and 11 human tumor cells. (A) Amplification of SRS19-6MuLV DNA in 15 mouse tumor cells. Lanes 1-15 are DCS, YAC-1, P3/NSI/7-A, MEL, RAW264.7, P19, LA795, MFC, B16, B16F1, Ca761, P815, CT26.WT, Hepa1-6 and EL4, respectively. Lane 16 is $\mathrm{H}_{2} \mathrm{O}$ as the negative control. Lane M is 100 bp plus DNA ladder. (B) Amplification of SRS19-6MuLV DNA in 12 murine normal cells/tissues. The 12 murine normal cells/tissues (Lanes 2-13) are the spleen of 615 mouse, lung of 615 mouse, spleen of KM mouse, lung of KM mouse, NIH/3T3, 3T3-L1, WEHI-3, FDC-P1, J774.A.1, NSC34, 3T3-swiss and BalB/c3T3, respectively. Lane 1 is DCS as the positive control and Lane 14 is $\mathrm{H}_{2} \mathrm{O}$ as the negative control. Lane M is 100 bp plus DNA ladder. (C) Amplification of SRS19-6MuLV DNA in 2 mouse tumor tissue samples. Lanes 2 and 3 are LII and FC, respectively. Lane 1 is DCS as the positive control and Lane 4 is $\mathrm{H}_{2} \mathrm{O}$ as the negative control. Lane M is 100 bp plus DNA ladder. (D) Amplification of SRS19-6MuLV DNA in SRSV/3T3 cells. Lane 2 is SRSV/3T3. Lane 1 is DCS as positive control and Lane 3 is $\mathrm{H}_{2} \mathrm{O}$ as negative control. Lane M is 100 bp plus DNA ladder. (E) Amplification of SRS19-6MuLV DNA in 11 human tumor cells. The 11 human tumor cells (Lanes 2-12) are K562, THP-1, Daudi, HL60, Calu-3, MD-MB-435S, HGC-27, Hela, HT-29, HepG2 and HCT116, respectively. Lane 1 is DCS as the positive control and Lane 13 is $\mathrm{H}_{2} \mathrm{O}$ as the negative control. Lane $\mathrm{M}$ is 100 bp plus DNA ladder. 
A

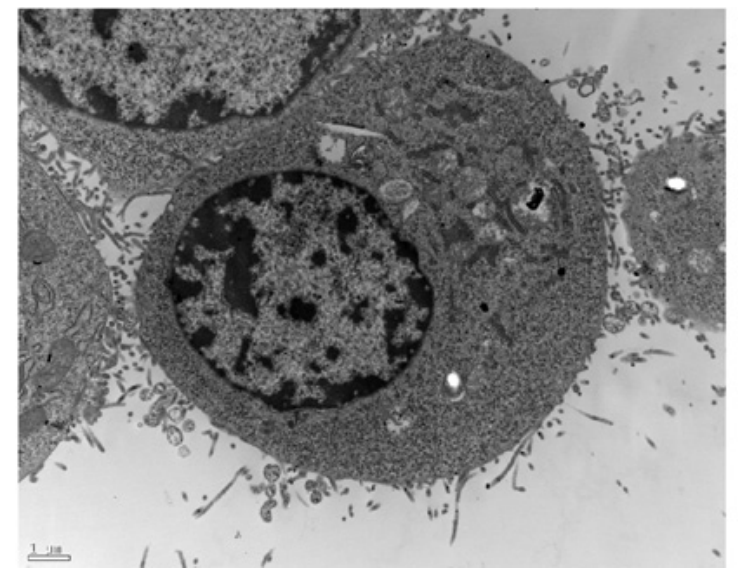

B

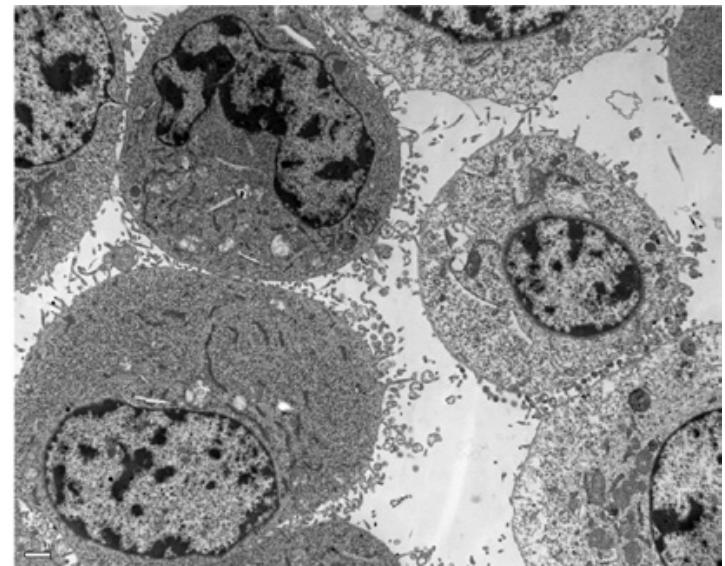

Figure 3. Electron microscopic observations on the virus particles in DCS and SRSV/3T3 cells. No virus particles were observed in (A) DCS and (B) SRSV/3T3 cells. Original magnification, x10,000.

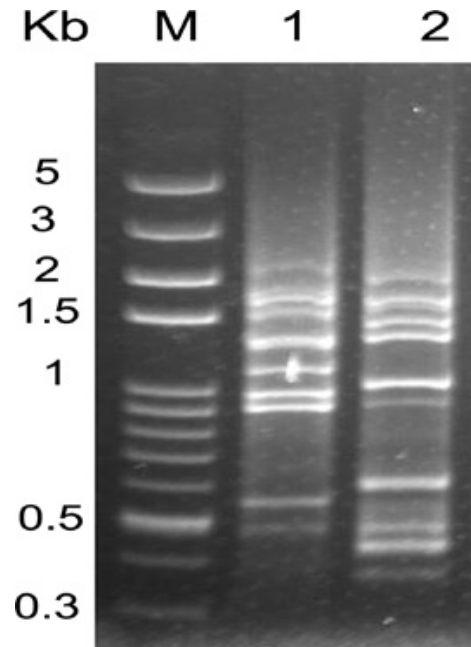

Figure 4. Amplification of SRS19-6MuLV integration sites. Lane 1 is DCS and Lane 2 is SRSV/3T3 cells. Lane M is 100 bp plus DNA ladder.

and the SRSV/3T3 cell genome contains an SRS19-6MuLV DNA fragment.

Determination of SRS19-6MULV DNA in 11 human tumor cells. To check the carcinogenic species-specificity, the 1,401-bp fragment of SRS19-6MuLV DNA was amplified in 4 human blood system tumor cells (K562, THP-1, Daudi and HL-60) and 7 other human tumor cells. Analysis of PCR products by $1 \%$ gel electrophoresis (Fig. 2E) revealed that human tumor cells were negative, indicating that SRS19$6 \mathrm{MuLV}$ does not infect human cells.

Electron microscopic observations of the virus particles in DCS and SRSV/3T3 cells. No virus particles were observed in DCS or SRSV/3T3 cells by TEM (Fig. 3), indicating that the SRS19-6MuLV virus particles do not exist in these two cell lines.

Cloning SRS19-6MuLV integration sites in DCS and SRSV/3T3 cells. For further study of the role of SRS19-6MuLV in the tumorigenesis of mouse DCS, SRS19-6MuLV integration sites were amplified by IPCR in DCS and SRSV/3T3 cells. Analysis of the second-round PCR products by $1 \%$ gel electrophoresis revealed that there were multiple integration sites of SRS19-6MuLV in both DCS and SRSV/3T3 cells (Fig. 4). Subsequently, gel-purified PCR products were cloned into the pMD19-T vector. Clones $(n=20)$ of DCS and SRSV/3T3 were determined by PCR using universal primers for the pMD19-T vector. Of the 20 amplified fragments, 14 were singled out and sequenced (Sangon).

Bioinformatics analysis of SRS19-6MuLV integration sites in mouse DCS and SRSV/3T3. The authenticated integration site sequences were singled out of those 14 clones and the same sequences were removed. Subsequently, 7 integration sites for SRS19-6MuLV were detected in DCS and 3 were detected in SRSV/3T3 (Table II). This result is consistent with the characteristics of the retrovirus. A common integration site for SRS19-6 MuLV in both DCS and SRSV/3T3 was identified in chromosome 6B3 (Table II), indicating that the integration of SRS19-6MuLV may have a preference for this site.

Many retroviruses cause cancer by activating proto-oncogenes or by inhibiting tumor suppressor genes and enhancer elements in the proviral LTR influence gene expression over hundreds of kilobase pairs (kbp), and can affect several genes simultaneously. The identity of the nearest genes within \pm 50 and $100 \mathrm{kbp}$, miRNA within $\pm 100 \mathrm{kbp}$ and associated common fragile sites of each SRS19-6MuLV integration site were examined (Table II). We did not identify a common proto-oncogene or tumor suppressor associated with the SRS19-6MuLV integration sites. However, after analysis for association with common fragile sites and miRNA, 2 integration sites in common with the fragile sites Fra6B3 and Fra12C1 were observed. In addition, 3 integration sites were near miRNAs, such as miRNA801, miRNA683 and 3 let7 miRNA family members (miRNAlet7d, miRNAlet7f1 and miRNAlet7a-1), which are important tumor-associated miRNAs (Table II). These factors may play important roles in the tumorigenesis of mouse DCS.

\section{Discussion}

SRS19-6MuLV is closely associated with a variety of mouse leukemias. In the 1960s, Professor Yang Gang established an 
Table II. Characteristics of SRS19-6MuLV integration sites identified in murine DCS and SRSV/3T3 cells.

\begin{tabular}{|c|c|c|c|c|c|c|}
\hline \multirow[t]{2}{*}{ Cell no. } & \multicolumn{2}{|c|}{$\begin{array}{c}\text { Site of } \\
\text { integration }\end{array}$} & \multicolumn{2}{|c|}{$\begin{array}{l}\text { Gene(s) within indicated } \\
\text { distance of integration site }\end{array}$} & \multirow[t]{2}{*}{$\begin{array}{l}\text { miRNA within } \pm 100 \mathrm{kbp} \\
\text { of integration site }\end{array}$} & \multirow[t]{2}{*}{$\begin{array}{l}\text { Common } \\
\text { fragile site }\end{array}$} \\
\hline & Cytoband & $\begin{array}{l}\text { Nucleotide } \\
\text { position }\end{array}$ & $\pm 50 \mathrm{kbp}$ & $\pm 100 \mathrm{kbp}$ & & \\
\hline
\end{tabular}

\begin{tabular}{|c|c|c|c|c|c|c|}
\hline \multicolumn{7}{|c|}{ DCS } \\
\hline $1^{\mathrm{a}}$ & $6 \mathrm{~B} 3$ & 56874802 & $\begin{array}{l}\text { Nt5c3, V1rc21, } \\
\text { LOC100042317 }\end{array}$ & $\begin{array}{l}\text { Fkbp9, V1rc19 } \\
\text { V1rc10, EG434016 }\end{array}$ & & Fra6B3 \\
\hline 2 & $13 \mathrm{~A} 4$ & 43380635 & Gfod1 & Sirt5 & & \\
\hline 7 & $13 \mathrm{~A} 5$ & 48648456 & $\begin{array}{l}\text { Aw456871, } \\
\text { A83005F24Rik }\end{array}$ & 2fp169 & $\begin{array}{l}\text { miRNAlet7d, } \\
\text { miRNAlet7f1, } \\
\text { miRNAlet7a-1, } \\
\text { miRNA683 }\end{array}$ & \\
\hline 9 & $1 \mathrm{H} 2.3$ & 168899701 & $\begin{array}{l}\text { LOC622102, } \\
\text { C30014k22Rik }\end{array}$ & & & \\
\hline 10 & 4D2.3 & 131908746 & $\begin{array}{l}\text { Snhg3, Rcc1, } \\
\text { Trspap1, Phactr4, } \\
\text { LOC100039864 }\end{array}$ & $\begin{array}{l}\text { 9530096D07Rik, } \\
\text { Gmeb1, Taf12 }\end{array}$ & miRNA801 & \\
\hline 13 & $12 \mathrm{C} 1$ & $\begin{array}{l}55811004 \\
\text { or } 55839900\end{array}$ & $\begin{array}{l}\text { Eapp, LOC673582, } \\
\text { LOC } 100039735, \\
\text { LOC } 100039764\end{array}$ & $\begin{array}{l}\text { 1110002B05Rik, } \\
\text { Snx6 }\end{array}$ & & Fra12C1 \\
\hline 14 & $3 \mathrm{E} 1$ & 65796002 & $\begin{array}{l}\text { LOC100044387, } \\
\text { LOC630761, } \\
\text { EG624866 }\end{array}$ & & & \\
\hline \multicolumn{7}{|c|}{ SRSV/3T3 } \\
\hline $2^{\mathrm{a}}$ & $6 \mathrm{~B} 3$ & 56874802 & $\begin{array}{l}\text { Nt5C3, V1rc21, } \\
\text { LOC100042317 }\end{array}$ & $\begin{array}{l}\text { Fkbp9, V1rc19 } \\
\text { V1rc10, EG434016 }\end{array}$ & & Fra6B3 \\
\hline 12 & $15 \mathrm{~F} 1$ & 99546080 & $\begin{array}{l}\text { Gd1, Smarcd1, } \\
\text { Accn2, Lass3, } \\
\text { 2310016M24Rik, } \\
\text { LOC100043481 }\end{array}$ & $\begin{array}{l}\text { Racgap1, } \\
\text { Lima1, } \\
\text { LOC10043473 }\end{array}$ & & \\
\hline 13 & $5 \mathrm{~F}$ & 123225463 & $\begin{array}{l}\text { Camkk2, P2rx4, } \\
\text { Anapc5 }\end{array}$ & $\begin{array}{l}\text { Rnf34, Fbx100, } \\
\text { P2rx7 }\end{array}$ & & \\
\hline
\end{tabular}

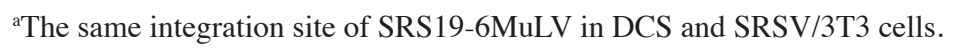

implantable LII solid-type reticulum cell sarcoma through subcutaneous inoculation with a suspension of spleen tissue from KM mice with spontaneous leukemia. Thereafter, a series of cell lines and tumor strains were established on the basis of LII (2). The most significant outcome was the TSZ complex containing more than 12 types of cell lines and tumor strains, including SRS ascites-type reticulum cell sarcoma, from which SRS19-6MuLV was separated. What renders this leukemia virus unusual is its ability to induce four types of leukemia, including erythroid, myeloid, T-lymphoid and B-lymphoid (1). Currently, the focus of study on SRS19-6MuLV is to understand the molecular mechanism of its multiple leukemogenesis $(12,13)$.

Our data support previous reports that SRS19$6 \mathrm{MuLV}$ induces DCS. The DCS cell line, originating from dendritic cells, was acquired by planting LII into 615 mice $(5,14)$. A cDNA expression library of DCS with mAb 983D4 was screened and a sequence with high homology to SRS19-6MuLV was obtained, which indicates a relationship between SRS19-6MuLV and DCS. We hypothesized that SRS19-6MuLV exists in DCS and may play an important role in its carcinogenic ability. First, the existence of a 1,401-bp fragment of SRS19-6MuLV was identified containing the PRO-HV region in DCS and MFC cells, but not in 13 other tumor cell lines, thus excluding the possibility that the genomes of mouse normal cells/tissues contain SRS19-6MuLV DNA fragments. In accordance with our expectations, this specific fragment was detected in LII, the parent tumor tissue of DCS, but not detected in FC, the parent tumor of MFC. Since LII was derived from KM mouse spontaneous leukemia, SRS19-6MuLV may participate in the process of its tumorigenesis. It is most likely that this virus infected MFC cells during the process of subculture, and this virus is not the carcinogen. Our results expand the spectrum of tumorigenesis of SRS19-6MuLV to include not only erythroid, myeloid, T-lymphoid and B-lymphoid leukemias, 
but also DC tumors. Another cell line, SRSV/3T3, was also observed, which originated from NIH/3T3 cells infected with the supernatant of SRS cells (2), containing this DNA fragment of SRS19-6MuLV. This virus-specific fragment was not detected in 11 human tumor cell lines, which means that this murine leukemia virus is not involved in human tumorigenesis.

No virus particles were observed in DCS and SRSV/3T3 cells by TEM, indicating that the SRS19-6MuLV did not replicate in these two cells. The following results prove that the virus had integrated into their genomes.

Altered expression of tumor suppressors or protooncogenes induced by retrovirus integration is one important mechanism of tumorigenesis (7). To further study the pathogenesis of SRS19-6MuLV, IPCR was used to search for the integration sites of SRS19-6MuLV in DCS and SRSV/3T3 cells. Although IPCR has some limitations, for example, in selecting appropriate restriction enzymes or the possibility of multiple DNA fragments cloning into the $\mathrm{T}$ vector, this method is superior for searching for integration sites accurately and precisely. In this study, 7 integration sites for SRS19-6MuLV were detected in DCS and 3 integration sites were detected in SRSV/3T3. It was found that SRS19$6 \mathrm{MuLV}$ had a common integration site in these two cells, located in chromosome $6 \mathrm{~B} 3$, indicating that the integration of SRS19-6MuLV may have a preference for this site. The identity of the nearest genes within \pm 50 and $100 \mathrm{kbp}$, miRNA within $\pm 100 \mathrm{kbp}$ and associated common fragile sites of each SRS19-6MuLV integration site were examined. Although there were some tumor-associated genes around the integration sites, such as $\mathrm{Nt} 5 \mathrm{c} 3(15,16)$, we did not find any important oncogenes or tumor suppressor genes. Additionally, 2 integration sites were located in the mouse common fragile sites, Fra6B3 and Fra12C1 (17). Previous studies have revealed that common fragile sites are extremely unstable in the process of carcinogenesis and are always destroyed and rearranged in many tumor cells $(18,19)$. Researchers have noted that most miRNAs play significant roles in tumorigenesis and metastasis (20). miRNAlet7d, miRNAlet7f1 and miRNAlet7a-1, members of the let7 miRNA family, were found to be located 14-17 $\mathrm{Kb}$ downstream of the integrated SRS19-6MuLV. The let7 miRNA family is closely related to certain tumors through the regulating oncogene RAS, such as carcinomas of the lung, breast and ovary (21-23). We speculate that these factors may play important roles in SRS19-6MuLV-induced DCS.

In conclusion, SRS19-6MuLV DNA integrated into DCS genomic DNA and was involved in the tumorigenesis of DCS. This finding expands our knowledge regarding SRS19$6 \mathrm{MuLV}$. Not only can it induce four types of leukemia, but it also causes DCS. Infection by this virus is species-specific and it is not present in human cell lines. By integration, SRS19-6MuLV may alter the expression of genes and miRNA near the integration sites.

\section{Acknowledgements}

The authors thank Professor Lianhua Yin (Shanghai Medical College of Fudan University) for kindly providing the SRSV/3T3 cell lines.

\section{References}

1. Bundy L, Ru M, Zheng B, et al: Biological characterization and molecular cloning of murine $\mathrm{C}$-type retroviruses derived from the TSZ complex from mainland China. Virology 212: 367-382, 1995.

2. Wang HW and Cheng L: Experimental Oncology Basic. People's Medical Publishing House, Beijing, 1992.

3. Duan DY, Liu YQ, Gao J, Gu B and Zhao XM: The clone of 3'-cDNA sequence of SRS19-6MuLV in DCS cells. Chinese J Immunol 17: 51-52, 2001.

4. Duan DY, Zhao XM, Gao J, Liu YQ and Gu B: Preparation and identification of a rat monoclonal antibody of DCS cells membrane protein. Chinese J Microbiol Immunol 18: 219, 1985.

5. Zhou S, Liu Y, Weng J, et al: Expression profiles of mouse dendritic cell sarcoma are similar to those of hematopoietic stem cells or progenitors by clustering and principal component analyses. Biochem Biophys Res Commun 331: 194-202, 2005.

6. Chen Y, Gu B, Wu S, et al: Using enrichment index for quality control of secretory protein sample and identification of secretory proteins. J Mass Spectrometry 44: 397-403, 2009.

7. Mikkers $\mathrm{H}$ and Berns A: Retroviral insertional mutagenesis: tagging cancer pathways. Adv Cancer Res 88: 53-99, 2003.

8. Silver J and Keerikatte V: Novel use of polymerase chain reaction to amplify cellular DNA adjacent to an integrated provirus. J Virol 63: 1924-1928, 1989.

9. Kim S, Kim N, Dong B, et al: Integration site preference of xenotropic murine leukemia virus-related virus, a new human retrovirus associated with prostate cancer. J Virol 82: 9964-9977, 2008.

10. Jin YF, Ishibashi T, Nomoto A and Masuda M: Isolation and analysis of retroviral integration targets by solo long terminal repeat inverse PCR. J Virol 76: 5540-5547, 2002.

11. Bundy LM and Fan H: Molecular and phylogenetic analysis of SRS 19-6 murine leukemia virus. Virus Genes 18: 65-79, 1999.

12. Granger SW, Bundy LM and Fan H: Tandemization of a subregion of the enhancer sequences from SRS 19-6 murine leukemia virus associated with T-lymphoid but not other leukemias. J Virol 73: 7175-7184, 1999.

13. Jahid S, Bundy LM, Granger SW and Fan H: Chimeras between SRS and Moloney murine leukemia viruses reveal novel determinants in disease specificity and MCF recombinant formation. Virology 351: 7-17, 2006.

14. Li CX, Gu B and Gao J: Establishment and identification of a dendritic cell sarcoma cell line (DCS): I cytology, histochemistry and immunohistochemistry. Acta Anatomica Sinica 12: 63-68, 1997.

15. Kim J, Sohn H, Yoon S, et al: Identification of gastric cancerrelated genes using a cDNA microarray containing novel expressed sequence tags expressed in gastric cancer cells. Clin Cancer Res 11: 473-482, 2005.

16. Shimizu S, Seki N, Sugimoto T, et al: Identification of molecular targets in head and neck squamous cell carcinomas based on genome-wide gene expression profiling. Oncol Rep 18: 1489-1497, 2007.

17. Elder F and Robinson T: Rodent common fragile sites: are they conserved? Evidence from mouse and rat. Chromosoma 97: 459-464, 1989.

18. Helmrich A, Stout-Weider K, Hermann K, Schrock E and Heiden T: Common fragile sites are conserved features of human and mouse chromosomes and relate to large active genes. Genome Res 16: 1222-1230, 2006.

19. Helmrich A, Stout-Weider K, Matthaei A, Hermann K, Heiden T and Schrock E: Identification of the human/mouse syntenic common fragile site FRA7K/Fra12C1-Relation of FRA7K and other human common fragile sites on chromosome 7 to evolutionary breakpoints. Int J Cancer 120: 48-54, 2007.

20. Garzon R, Marcucci G and Croce C: Targeting microRNAs in cancer: rationale, strategies and challenges. Nat Rev Drug Discov 9: 775-789, 2010.

21. Johnson S, Grosshans H, Shingara J, et al: RAS is regulated by the let-7 microRNA family. Cell 120: 635-647, 2005.

22. Ohshima K, Inoue K, Fujiwara A, et al: Let-7 microRNA family is selectively secreted into the extracellular environment via exosomes in a metastatic gastric cancer cell line. PLoS One 5: e13247, 2010.

23. Sampson V, Rong N, Han J, et al: MicroRNA let-7a downregulates MYC and reverts MYC-induced growth in Burkitt lymphoma cells. Cancer Res 67: 9762-9770, 2007.22 